\title{
Endemias rurais, saúde e desenvolvimento: Emmanuel Dias e a construção de uma rede de aliados contra a doença de Chagas
}

\author{
Rural endemic diseases, health and development: Emmanuel Dias \\ and the construction of a network of allies against Chagas disease
}

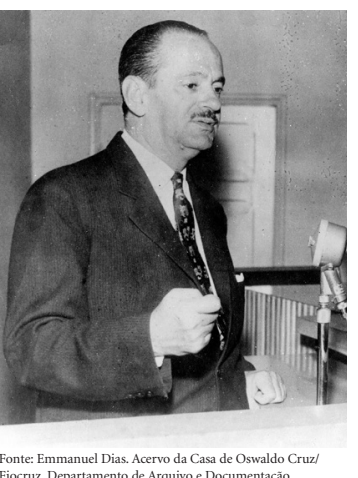

Abstract The scope of this article is to analyze the trajectory of Emmanuel Dias (1908-1962), a researcher at the Oswaldo Cruz Institute (OCI) and director of the Center for Studies and Prophylaxis of Chagas Disease (OCI outpost established in 1943 in the city of Bambui, Minas Gerais), as a key actor in the acknowledgement of Chagas disease as a public health problem in Brazil and the Americas. It seeks to show that the conquest of this acknowledgement, the cornerstone of which was the staging of the first campaign to combat the disease in Brazil in 1950, was made possible by the intense political mobilization of Dias together with the various social groups, such as physicians, politicians and residents of rural areas, public health officials, governments and international organizations. This mobilization occurred during the 1940s and 1950s in a historical context marked by intense debate about the relationship between health and development and helped to construct a network of alliances that was critical for the recognition of Chagas disease as a chronic cardiopathy, which threatened the productivity of rural workers and represented a medical and social problem that merited public health actions and programs geared to get it under control.

Key words Emmanuel Dias, Endemic rural diseases, History of health, Development, Chagas disease
Resumo O objetivo deste artigo é analisar a atuação de Emmanuel Dias (1908-1962), pesquisador do Instituto Oswaldo Cruz (IOC) e diretor do Centro de Estudos e Profilaxia da Moléstia de Chagas (posto do IOC criado em 1943 na cidade de Bambuí, Minas Gerais), como ator decisivo no processo de reconhecimento da doença de Chagas como problema de saúde pública no Brasil e no continente americano. Busca-se evidenciar que a conquista deste reconhecimento, que teve como marco fundamental a realização da primeira campanha de combate à enfermidade no Brasil em 1950, foi viabilizada pela intensa mobilização politica de Dias junto a diversos grupos sociais, como médicos, políticos e moradores das áreas rurais, profissionais dos serviços públicos de saúde, governos e associações internacionais. Tal mobilização, ao longo das décadas de 1940 e 1950, num contexto histórico marcado por intensos debates sobre as relações entre saúde e desenvolvimento, levou à construção de uma rede de apoios decisiva para que a doença, caracterizada como cardiopatia crônica a ameaçar a produtividade do trabalhador rural, fosse considerada um problema médico-social a merecer ações e programas de saúde pública voltados para seu controle.

Palavras-chave Emmanuel Dias, Endemias rurais, História da saúde, Desenvolvimento, Doença de Chagas
4036/401, Manguinhos.

21040-361 Rio de Janeiro

RJ Brasil.

simonekropf@yahoo.com.br 


\section{Introdução}

Como tornar uma doença objeto de um programa de saúde pública? Além dos meios científicos e técnicos para viabilizá-lo, há que se dispor do reconhecimento, pela sociedade, de que se está diante de um problema a merecer ações do Estado. É preciso garantir também o apoio necessário aos profissionais a quem se confia a condução destas ações. No entanto, longe de constituir um processo linear ditado pelo saber e pela técnica de especialistas, o processo de reconhecimento e enfrentamento de um problema de saúde pública traz à cena um conjunto muito mais matizado $\mathrm{e}$ variado de atores, estratégias, interesses, disputas e alianças.

Abordarei neste artigo um personagem que exerceu papel decisivo na saúde pública brasileira de meados do século XX ao colocar o tema das endemias rurais, mais especificamente da doença de Chagas, na agenda do debate nacional e das políticas sanitárias. Emmanuel Dias (1908-1962) assumiu a liderança dos estudos sobre a doença nas décadas de 1940 e 1950 e, como diretor do Centro de Pesquisas e Profilaxia da Moléstia de Chagas (CEPMC), posto do Instituto Oswaldo Cruz (IOC) na cidade mineira de Bambuí, produziu as condições para que a enfermidade descrita por Carlos Chagas (1878-1934) na pequena cidade de Lassance (Minas Gerais), em 1909, fosse consensualmente reconhecida como fato médico-científico e questão de saúde pública ${ }^{1}$.

Num contexto marcado pelo debate sobre as relações entre saúde, desenvolvimento e produtividade do trabalho, e pelo otimismo quanto às novas "armas" para se vencer as chamadas doenças tropicais (como os inseticidas de ação residual), Dias e seus colaboradores, dentro e fora do laboratório, foram além das bandeiras defendidas nas décadas de 1910 e 1920 por Carlos Chagas e os partidários do movimento médico-higienista pelo saneamento rural. Eles criaram as condições - científicas, sociais e políticas - para que tais bandeiras se traduzissem em ações concretas de combate à endemia que havia sido o símbolo dos que clamaram pela saúde pública nos sertões: estabeleceram o quadro clínico pelo qual a doença seria reconhecida como enfermidade cardíaca crônica, identificaram um inseticida capaz de agir contra o inseto vetor e articularam a primeira campanha de combate à doença, conduzida pelo Ministério da Educação e Saúde em $1950^{1}$.

Meu argumento é o de que tal processo de reconhecimento da doença de Chagas como problema médico-social e questão de saúde pública decorreu diretamente do engajamento de Dias no sentido de criar uma ampla e diversa rede em torno desta enfermidade, arregimentando aliados que, em distintas esferas da vida social, atuaram não como meros divulgadores ou apoiadores dos conhecimentos e ações preconizados pelos cientistas, mas como atores fundamentais na própria produção e legitimação destes saberes e práticas. A conquista desta adesão dependeu da peculiar capacidade de Dias de fazer estes diversos grupos vislumbrarem no estudo e/ou no controle desta enfermidade seus próprios interesses e identidades específicas. Articulando clínicos rurais, moradores das áreas endêmicas, governos, profissionais de saúde, agências de saúde internacional, imprensa, entre outros, a rede montada por Dias constitui um exemplo emblemático daquilo que os historiadores vêm assinalando como a dimensão coletiva e social da produção dos conhecimentos e dos fatos científicos e, além disso, um caso elucidativo dos processos e das dinâmicas pelos quais os temas da saúde são construídos mediante complexas e múltiplas articulações entre ciência, política e sociedade.

\section{As pesquisas após a morte de Carlos Chagas}

Nascido na cidade do Rio de Janeiro, aos 27 de julho de 1908, Emmanuel Dias era filho de Ezequiel Dias (1880-1922), o qual, ainda durante o curso médico, passou a integrar a primeira equipe de pesquisadores do Instituto Soroterápico Federal. Criado em 1900 para fabricar soros e vacinas contra a peste bubônica que ameaçava atingir a capital federal, o Instituto de Manguinhos, sob a liderança de Oswaldo Cruz, expandiria suas atividades a partir de 1908, de modo a tornar-se, além de produtor de imunobiológicos, um centro de pesquisa e ensino em microbiologia e medicina tropical ${ }^{2}$. Assim como o pai, Emmanuel iniciou suas atividades no IOC como estudante, em 1929, em caráter voluntário, sob a supervisão direta de Carlos Chagas, de quem era afilhado de batismo. Tendo feito o Curso de Aplicação de Manguinhos (especialização destinada à formação de pesquisadores em medicina experimental) em 1932, formou-se pela Faculdade de Medicina da Universidade do Rio de Janeiro em 1933, com tese de doutoramento sobre o ciclo evolutivo do Trypanosoma cruzi, causador da doença de Chagas. Nesse ano, foi contratado por Chagas, diretor do IOC, como adjunto de Thales Martins, chefe da seção de fisiologia. Em 1935, foi enviado para trabalhar no Instituto Biológico Ezequiel Dias, filial do IOC em Belo Horizonte. Lá estabeleceu 
contato com Amilcar Vianna Martins, catedrático de parasitologia da Faculdade de Medicina de Belo Horizonte que, em 1940, iria identificar um importante foco da doença de Chagas em Bambuí (MG), onde, em dezembro de 1943, o IOC inauguraria um posto especial para o estudo da enfermidade, o CEPMC, cuja direção coube a Dias até seu falecimento em $1962^{1,3}$.

A importância do trabalho realizado em Bambuí para o reconhecimento científico e social da doença de Chagas diz respeito ao enfrentamento e à superação das incertezas e dos questionamentos que, desde o início da década de 1920, cercavam o tema. Apesar do reconhecimento inicial de que a descoberta da nova tripanossomíase humana tinha sido um grande feito da ciência brasileira, e da grande visibilidade que os estudos sobre a enfermidade alcançaram no debate nacionalista da década de 1910 sobre os prejuízos causados pelas endemias rurais ao progresso do país, a doença foi objeto de acirrada controvérsia entre 1922 e 1923 na Academia Nacional de Medicina. Alguns médicos, capitaneados pelo catedrático de Higiene da Faculdade de Medicina do Rio de Janeiro Afrânio Peixoto, lançaram dúvidas sobre sua importância médico-social, afirmando que equívocos na caracterização clínica proposta por Chagas (como a associação entre a infecção pelo T. cruzi e o bócio endêmico) haviam levado a um exagero em sua qualificação como flagelo de grandes proporções no país. A dificuldade então existente para o diagnóstico parasitológico na fase crônica da doença (na qual se situa a maioria dos casos) contribuía para fortalecer tais críticas, que afirmavam tratar-se não de uma tripanossomíase americana, mas do "mal de Lassance", em referência ao pequeno povoado mineiro onde fora descrita. Para além dos conteúdos científicos em questão, tratava-se de um embate político: os contendores de Chagas afirmavam que a ideia de um "Brasil doente", preconizada pelos adeptos do movimento sanitarista, traria descrédito ao país e afugentaria capitais e imigrantes. A controvérsia, de grande repercussão, trouxe um ambiente de dúvidas sobre a doença, apesar da continuidade dos estudos de Chagas e seus colaboradores ${ }^{4}$.

Após o falecimento de Carlos Chagas, em novembro de 1934, as pesquisas prosseguiram sob a liderança de seu filho mais velho, Evandro Chagas (1905-1940), que em 1937 criou no IOC o Serviço de Estudo de Grandes Endemias (SEGE). O projeto era criar, em cooperação com os governos estaduais, institutos para estudar as principais doenças do interior do país e propiciar aos serviços sanitários instrumentos para o

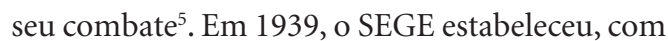
pesquisadores do Instituto Biológico Ezequiel Dias (que em 1937 havia sido transferido ao governo estadual), um plano de estudo da doença de Chagas em Minas Gerais, que levaria à identificação em 1940 (ano em que Evandro Chagas faleceu vítima de um acidente aéreo) do foco da doença em Bambuí ${ }^{1}$.

No início da década de 1940, com a adesão ao esforço de guerra do governo brasileiro, o IOC passou a atender a novas demandas do Ministério da Educação e Saúde (MES), o que gerou condições institucionais favoráveis para que seu diretor, Henrique Aragão, intensificasse as pesquisas que expressassem a tradicional vocação do instituto de servir à saúde pública, como o estudo das endemias rurais. Num momento em que eram desenvolvidos novos recursos profiláticos e terapêuticos (como o DDT e a penicilina) contra as doenças infecciosas que ameaçavam os soldados no front, Aragão fundou postos em várias regiões do país para estudar doenças endêmicas, entre elas o CEPMC ${ }^{1}$. Tal perspectiva beneficiou-se também dos significados que o tema das endemias rurais assumia no contexto nacional do pós-1930. Ainda que o projeto de modernização do primeiro governo de Getúlio Vargas (1930-1945) privilegiasse o mundo urbano-industrial, a melhoria da produção agrícola era vista como fundamental para o abastecimento do crescente mercado interno. Além disso, a centralidade conferida ao trabalho como valor primordial para a construção de uma "nova nação" fornecia justificativa política e ideológica a projetos que propiciassem a existência de trabalhadores saudáveis, fortes e produtivos, nas cidades e no campo ${ }^{6}$.

Do ponto de vista da agenda de pesquisas, o CEPMC tinha dois objetivos ${ }^{7}$. Primeiramente, avançar na caracterização clínica da doença de Chagas, sobretudo quanto a seus aspectos cardíacos, indicados por Chagas desde 1910, mas ofuscados pela primazia que ele conferiu à associação com o bócio (enunciado que, após sua morte, viria a ser descartado). Nesta frente de investigação, foi decisiva a atuação do cardiologista Francisco Laranja, convidado por Dias a integrar a equipe de Bambuí em 1943. Esta seria uma aliança fundamental, num momento em que a cardiologia se institucionalizava como especialidade no campo médico brasileiro e em que as doenças crônico-degenerativas, como as enfermidades cardiovasculares, ganhavam grande visibilidade no debate político sobre a proteção social aos trabalhadores ${ }^{1,8}$. Cardiologista do In- 
stituto de Aposentadoria e Pensões dos Industriários, Laranja possuía uma expertise clínica que, valendo-se das modernas técnicas de eletrocardiografia, seria determinante para definir o quadro clínico e eletrocardiográfico específico da cardiopatia chagásica crônica ${ }^{9}$. Além desta frente de investigação, o CEPMC investiria também na busca por estratégias de prevenção da doença, por meio do ataque aos transmissores e mediante técnicas de melhoria nas habitações. Com a colaboração do médico mineiro José Pellegrino, Dias estabeleceu em 1948 a ação do gamexane (BHC) contra os barbeiros ${ }^{10}$.

Além da colaboração preciosa destes e de outros médicos e pesquisadores que compunham a equipe do CEPMC, Dias precisava recrutar outros aliados para aquele empreendimento que, para ele, se tornaria uma verdadeira "cruzada” contra a doença. Um dos primeiros e principais "elos" desta rede seriam os médicos das áreas rurais.

\section{A aliança com os clínicos do interior}

Aprofundando uma orientação já praticada pelo SEGE, Dias empenhou-se em chamar a atenção dos médicos do interior para a doença de Chagas. Para isso, publicava artigos em revistas médicas de grande circulação com informações básicas sobre os principais indícios da doença existência de barbeiros e sinais clínicos da fase aguda, como o sinal de Romaña, descrito pelo argentino Cecilio Romaña em 1935 - e orientações sobre como proceder diante destes indícios. Salientava que o estudo e o mapeamento da enfermidade não poderiam prescindir da colaboração dos médicos locais, já que eram estes - e não os cientistas - que estavam em contato rotineiro com a população das áreas endêmicas ${ }^{11,12}$.

Para viabilizar esta parceria entre a ciência do laboratório e a prática clínica, Dias prontificava-se a enviar a estes médicos lâminas para observação ao microscópio, ampolas para coleta de sangue, caixas para o acondicionamento de barbeiros, publicações especializadas e demais instruções necessárias. Além disso, oferecia a chancela do IOC à publicação de artigos em que tais clínicos descrevessem casos da doença por eles registrados e/ou estudados em seus consultórios. Orgulhosos por atuarem como colaboradores do renomado Instituto de Manguinhos, estes médicos não apenas trouxeram a público novos indícios da ocorrência da doença, mas, valendo-se de sua influência junto à população, passaram a atuar como peças importantes na dis- seminação dos conhecimentos e na mobilização local em torno do assunto ${ }^{13-16}$.

Expressando uma associação que rendia benefícios mútuos, o médico de Uberaba Rubem Jácomo, por exemplo, escreveu a Dias em 1947 contando que já havia registrado mais de sessenta casos em seu consultório e que estava empenhado em distribuir na região, especialmente entre fazendeiros, o folheto que Dias havia publicado sobre a doença. Dizia o clínico: "Tenho feito uma propaganda muito grande perante os colegas e o povo. Recebo diariamente várias caixas de barbeiros para exame"17. Estimulado por Dias a publicar seus achados, Jacomo se tornaria uma liderança local no estudo da doença e na viabilização da campanha de $1950^{18}$.

Alguns médicos de áreas rurais viriam inclusive a contribuir para as investigações que o CEPMC realizava sobre a cardiopatia chagásica. Clinicando em Uberlândia, Miron de Menezes publicou em 1949 um artigo em que, com base em centenas de traçados eletrocardiográficos colhidos em "lavradores de todo o Brasil Central", corroborava a tese sobre a importância da doença de Chagas como fator etiológico de cardiopatias em amplas zonas rurais do Brasil, a causar morte súbita ou insuficiência cardíaca em trabalhadores em plena idade produtiva ${ }^{16}$.

A divulgação de informações sobre a doença por meio de folhetos impressos pelo Serviço Nacional de Educação Sanitária e de artigos ilustrados em revistas voltadas para o grande público, como a Eu Sei Tudo, maximizava a circulação dos conhecimentos produzidos no posto de Bambuí, não só entre os clínicos, mas também junto a amplas audiências ${ }^{19,20}$.

\section{A mobilização em Minas Gerais}

Em Minas Gerais, o tema da produtividade do trabalho rural ganhou especial importância no pós-II Guerra, quando o estado viveu o ápice dos esforços por parte do poder público para superar a situação de atraso e estagnação econômica que vinha levando à queda na produtividade agrícola e ao êxodo rural. O Plano de Recuperação Econômica e Fomento da Produção, formulado em 1947 pelo governador Milton Campos, buscava promover a modernização da agricultura de modo a recuperar o protagonismo de Minas como "celeiro" do país ${ }^{21}$. A ênfase na necessidade de aumentar o rendimento do "capital humano" como fator de produção fazia da saúde, particularmente do controle das endemias rurais, um elemento estratégico para a recuper- 
ação econômica. A União Democrática Nacional (UDN), partido que elegeu em 1946 o governador Milton Campos, vinha manifestando, desde a campanha eleitoral, interesse pelo problema da doença de Chagas, chegando a publicar em jornais um plano de ação contra a endemia ${ }^{1}$.

Nesse contexto, os políticos mineiros seriam alvo das investidas do diretor do CEPMC. Em 1947, Campos autorizou a construção de uma nova sede para o posto, cuja inauguração se daria em $1951^{1}$. Neste mesmo ano, por meio de circular publicada no jornal Minas Gerais, o Superintendente do Departamento de Municipalidades, Orlando de Carvalho, exortou os prefeitos do estado a atenderem a solicitação de Henrique Aragão para colaborar com o IOC no estudo e no controle da doença de Chagas. Os prefeitos deveriam enviar barbeiros para exame, promover campanhas de educação sanitária, especialmente nas escolas, estimular melhorias nas habitações populares, além de procurar envolver nesta campanha médicos, sanitaristas, laboratoristas, farmacêuticos e professoras em seus municípios, inclusive enviando ao Instituto uma lista das pessoas que lhes parecessem com maior disposição e capacidade para colaborar. A circular informava que Dias enviaria folhetos e qualquer material necessário ${ }^{22}$.

O próprio Dias engajou-se em arregimentar a população das áreas rurais, especialmente em Minas. Além da distribuição de folhetos e da publicação de matérias em jornais locais, uma estratégia para atrair os moradores de Bambuí e das regiões vizinhas foi o oferecimento, no posto, de assistência médica e de medicamentos gratuitos, o que favorecia tanto a divulgação dos conhecimentos sobre a doença quanto o registro de novos $\operatorname{casos}^{1}$

O apoio desses diversos grupos sociais - médicos, políticos, moradores das áreas endêmicas - era importante para a conquista de um elo decisivo na cadeia de associações construída por Dias: as autoridades sanitárias responsáveis por campanhas de controle de endemias, tanto nos níveis federal e estadual, quanto no que se refere às agências internacionais, como a Organização Sanitária Pan-Americana (OSP, posteriormente Organização Pan-americana da Saúde/OPAS). A partir de 1948, quando se declarou comprovada experimentalmente a eficácia do gamexane contra os barbeiros ${ }^{10}$ e, ao mesmo tempo, o grupo de Bambuí considerou sistematizados os conhecimentos clínicos sobre a cardiopatia chagásica crônica $^{23}$, Dias destinou sua militância ao convencimento de que era possível e urgente implementar ações de controle.
Naquele ano, na VI Conferência Pan-Americana de Diretores de Saúde, realizada na Cidade do México, conclamou a OSP e os diretores nacionais de saúde dos países do continente a organizar um programa sistemático de combate aos barbeiros $^{24}$. Em 1949, aconteceria na Argentina a Primeira Reunião Pan-Americana de Doença de Chagas, promovida pela OSP. Pela primeira vez pesquisadores de diversos países americanos reuniam-se em fórum específico para debater a endemia. Todavia, mesmo conquistando avanços na luta para ampliar a visibilidade política do assunto, Dias mantinha sua denúncia quanto à falta de iniciativas concretas para combatê-la, tanto da parte da OSP quanto do governo brasileiro ${ }^{25}$.

\section{Os médicos do Brasil Central e a primeira campanha contra a doença}

Se os médicos do interior vinham sendo aliados importantes para o diagnóstico de novos casos, o estudo clínico e a divulgação da importância da doença, eles também exerceriam papel decisivo para que o tema fosse inserido na agenda de saúde do Estado brasileiro. Tal apoio se deu em especial no âmbito dos chamados "Congressos Médicos do Brasil Central”, eventos que, por si só, expressavam o processo de valorização e afirmação social dos clínicos do interior como protagonistas no estudo e no encaminhamento político dos temas de saúde que afligiam os sertões do país. O primeiro destes congressos aconteceu em Uberaba, em 1947, e teve como tema principal a doença de Chagas. Ao afirmarem que eram eles e não os "médicos do litoral" quem lidava concretamente com os flagelos do interior do país, os médicos do Brasil Central - como eles próprios se designavam - passaram a usar o tema da importância médica e social da endemia chagásica para maximizar seus próprios interesses e afirmar sua identidade socioprofissional específica. Dias utilizou-se amplamente deste espaço para amplificar sua militância com vistas a inserir a doença de Chagas na pauta das políticas sanitárias do país ${ }^{1}$.

No III Congresso Médico do Triângulo Mineiro e Brasil Central, ocorrido em Araxá em 1949, Dias reafirmou a força da associação com os médicos do interior mediante homenagem ao próprio Carlos Chagas, reverenciado como exemplo da tradição de Manguinhos na articulação entre ciência e saúde pública e da centralidade que os "males do interior do Brasil" assumiam nesta tradição. Segundo Dias, Chagas foi essencialmente um "filho do interior, [que] 
triunfou nos grandes centros mundiais, mas para ele [interior] teve sempre o espírito voltado”. Ao apresentar, como de costume, os resultados das pesquisas do CEPMC, Dias conferiu particular destaque aos dados produzidos pelos médicos do interior sobre a dimensão geográfica e social da endemia no Brasil Central. Exortou os participantes do congresso a manifestar seu apoio àquela "causa" mediante moção dirigida ao ministro da Educação e Saúde, em prol da realização de uma "campanha redentora" de combate à endemia. A moção foi encaminhada pelo presidente do congresso, Sabino Vieira de Freitas, ao ministro Clemente Mariani ${ }^{26}$.

Depois de ensaios experimentais realizados em Uberaba sob a supervisão de Dias com vistas a estabelecer os procedimentos técnicos para uma campanha de desinsetização domiciliar contra os barbeiros, o MES, mediante a portaria n. 577, de 6 de dezembro de 1949, atribuiu ao Serviço Nacional de Malária (SNM), ao IOC e à Divisão de Organização Sanitária o encargo de organizarem com urgência um plano para dar início a esta campanha, a ser executado pelo SNM sob a orientação dos pesquisadores do CEPMC e com o apoio da Secretaria de Saúde e Assistência de Minas Gerais ${ }^{1}$. Em maio de 1950, na cidade de Uberaba, teve início a primeira campanha de combate à tripanossomíase americana no Brasil. A região escolhida para os expurgos compreendia 123 municípios de Minas Gerais, situados no Triângulo Mineiro e no sudoeste do estado, e 93 no norte de São Paulo, na bacia do Rio Grande. Previa-se a aplicação de inseticidas em cerca de duzentas mil habitações ${ }^{1,27}$.

A inauguração da campanha teve grande repercussão na imprensa, especialmente em Minas Gerais, e diversas reportagens registraram, em tom ufanista, o otimismo quanto ao poder da ciência e à capacidade de ação do Estado como instrumentos para a "redenção" dos sertanejos ${ }^{28}$. A campanha conferiu grande visibilidade às noções sobre a doença preconizadas pelo CEPMC, sobretudo sua caracterização como cardiopatia que ameaçava o trabalhador rural, e significou a conquista de um aliado imprescindível para o objetivo maior de Dias de inserir a endemia na agenda política e sanitária do país. O SNM era o mais importante organismo na estrutura federal da saúde pública brasileira, com grande penetração em vários estados, e que estava em evidência desde o pós-guerra, em razão do caráter emblemático conferido internacionalmente à malária como expressão da importância social e econômica das chamadas "doenças de massa" e, ao mesmo tempo, do otimismo da "era DDT". Seu diretor, Mário Pinotti, que estava à frente do serviço desde sua criação em 1941, seria forte liderança política da saúde pública na década de 1950, tornando-se ministro da Saúde entre 1958 e $1960^{29}$.

\section{A luta por uma campanha continental}

Materializando o reconhecimento da importância médico-social da doença de Chagas, a campanha de 1950 trouxe grande projeção ao tema nos fóruns médicos, científicos e de saúde pública. No Congresso Brasileiro de Higiene de 1951, por exemplo, foi o tema que reuniu maior quantidade de trabalhos. Tal projeção, por sua vez, contribuiu para ampliar este campo de pesquisa, que passaria a institucionalizar-se nas universidades, especialmente nas faculdades de medicina criadas em regiões onde a doença era endêmica, como Ribeirão Preto, Triângulo Mineiro e Goiânia ${ }^{1}$.

Ao longo da década de 1950, Dias permaneceria engajado na mobilização política para estender, para outras regiões do país, as ações iniciadas no Triangulo Mineiro. Além dos aliados que já conquistara na década de 1940, o diretor do CEPMC buscava novos meios de se fazer ouvir junto às autoridades sanitárias, inclusive recorrendo à própria população acometida pela doença, que já o reconhecia como autoridade no assunto. Em 1957, por exemplo, um telegrafista de Araxá enviou-lhe um barbeiro que havia picado seu filho junto a uma carta em que reclamava da falta de combate à doença naquela cidade. Solicitando a ajuda de Dias, declarou que o apoiaria em qualquer ação necessária para chamar a atenção das autoridades. Ao respondê-lo comunicando o resultado negativo do exame no barbeiro, Dias informou que havia remetido sua carta ao ministro da Saúde, como mais um meio de pressionar os serviços sanitários a empreender o combate aos vetores na região ${ }^{30}$.

A importância conferida pelo governo de Juscelino Kubitschek (1956-1961) ao desenvolvimento do interior, cujo símbolo foi a construção da nova capital no sertão goiano, favoreceu a visibilidade da doença de Chagas nos meios de comunicação, ampliando o alcance da mobilização de Dias. Em 1957, equipe da revista O Cruzeiro viajou por 35 municípios de São Paulo e produziu reportagem especial sobre a doença, que afirmava que o problema vinha "ameaçando o sertão paulista, justamente uma das faixas de terra mais produtivas do País" e clamava por medidas de 
controle $^{31}$. Em 1959, por ocasião das comemorações do cinquentenário da descoberta da enfermidade, o jornal $O$ Globo lançou uma grande campanha para apoiar as medidas conduzidas pelo Ministério da Saúde (MS) em Minas Gerais, fundando a Associação Brasileira de Combate à Doença de Chagas. Além de promover conferências, programas de rádio e distribuição de cartazes e folhetos educativos, o jornal enviou uma equipe para viajar por 20 dias, em avião cedido pelo MS, a várias cidades do interior mineiro, para documentar, numa série de reportagens e num filme, a situação da endemia no estado. Dias, embora não tivesse relação direta com a campanha, apoiou-a publicamente ${ }^{32}$.

Num indicio de que a rede criada por Dias mobilizava também interesses e agentes econômicos, a iniciativa de $O$ Globo foi apoiada pelo Instituto Brasileiro do Café, sob a justificativa de que o problema afetava diversas regiões cafeeiras do país. Os fazendeiros das regiões endêmicas também passariam a demandar ações de controle em suas terras. Em entrevista a O Globo, em 1959, um técnico do Departamento Nacional de Endemias Rurais (DNERu) relatava que, quando os guardas sanitários começaram, no início da década, a realizar expurgos nas moradias, os fazendeiros geralmente recusavam-se a abrir suas propriedades, mas que, com o decorrer do tempo, eles mesmos passaram a enviar barbeiros para os postos sanitários pedindo a aplicação de inseticidas $^{33}$.

À medida que avançavam as ações de combate à endemia no país, intensificadas com a criação do Departamento Nacional de Endemias Rurais (DNERu) pelo governo JK, Dias enfatizava que este era um problema não só brasileiro mas continental, que requeria o engajamento dos governos dos diversos países latino-americanos e uma ação coordenada da OSP. Em 1956, ano seguinte à inauguração pela Organização Mundial da Saúde (OMS) de uma campanha global de erradicação da malária, ele deu início em Bambuí a um ensaio de erradicação dos triatomíneos, com apoio financeiro da Comissão do Vale do São Francisco (CVSF). A ideia era estabelecer as bases técnicas para convencer a OSP a implementar uma campanha com tal objetivo nas Américas ${ }^{34}$.

O tema era polêmico. Numa época de intensos debates sobre se a superação do "círculo vicioso" da doença e da pobreza ${ }^{35}$ deveria ser alcançada mediante campanhas verticalizadas de combate aos transmissores ou por meio de medidas horizontais visando à promoção do desenvolvimento social e econômico, Dias enfrentou críticas tanto dos que preconizavam outras metodologias para a eliminação dos barbeiros quanto dos que discordavam da própria primazia ao combate ao vetor, defendendo a implementação de melhorias nas habitações rurais ${ }^{1}$.

Por meio de várias viagens e de intensa correspondência em 1957, o diretor do CEPMC buscou de modo incansável convencer cientistas, sanitaristas e governos de países latino-americanos a realizarem, a exemplo do que o CEPMC fazia em Bambuí, ensaios experimentais de erradicação de triatomíneos, como forma de pressionar a OSP a coordenar uma campanha desta natureza no continente, à semelhança do que vinha sendo implementado pela OMS para a malária. Apesar da boa acolhida junto aos colegas latino-americanos, em especial dos especialistas na Argentina, Uruguai e Venezuela, Dias ficava cada vez mais contrariado com a falta de respostas da OSP. Em 1958, em seus pronunciamentos em congressos científicos e por meio de cartas enviadas ao diretor da OMS, Marcolino Candau, a Fred Soper, diretor da OSP, e a Fernando Lobo, presidente do Conselho da Organização dos Estados Americanos, queixou-se enfaticamente da negligência com que os organismos sanitários internacionais tratavam a questão ${ }^{1,36}$.

Em 1959, o I Congresso Internacional de Doença de Chagas, que reuniu no Rio de Janeiro cerca de 400 estudiosos da doença, foi um marco importante a expressar a institucionalização do tema como objeto de uma cada vez mais ampla comunidade científica ${ }^{37}$. O apoio desta comunidade às reivindicações de Dias foi expresso mediante moção encaminhada à OPAS. No ano seguinte, a OMS promoveu, em Washington, o Grupo de Estudos sobre Doença de Chagas, reunindo especialistas de vários países para avaliar os avanços no conhecimento e discutir o planejamento de programas contra a endemia. Dias foi o chair da reunião. A despeito da falta de consenso quanto ao modelo a ser adotado no combate à doença, o relatório oficial do evento materializou o reconhecimento formal, no âmbito da OMS, de que a tripanossomíase americana, pela incapacitação ao trabalho que provocava, era um problema real para o desenvolvimento dos países americanos $^{38}$.

Em 23 de outubro de 1962, Dias faleceu em decorrência de um acidente rodoviário. Seu filho, João Carlos Pinto Dias, assumiu a direção do CPEMC, que na década de 1970 passou a vincular-se ao Centro de Pesquisas René Rachou, unidade da Fundação Oswaldo Cruz em Belo Horizonte, e, em 1980, recebeu o nome de Pos- 
to Avançado de Pesquisas Emmanuel Dias. Internacionalmente reconhecido por seus estudos em epidemiologia, clínica e controle da doença de Chagas e dando continuidade à mobilização política e social de seu pai, João Carlos Pinto Dias teve papel decisivo na luta contra a endemia, que em 1975 passou a contar com um programa específico, em nível nacional, no âmbito da Superintendência de Campanhas de Saúde Pública (SUCAM) do Ministério da Saúde, criada em 1970. Em 1985, assumiu a direção do Programa Nacional de Controle da Doença de Chagas, que levaria à interrupção da transmissão vetorial no país ${ }^{39,40}$.

\section{Considerações finais}

Apesar de não ter assistido à concretização de sua luta para que o controle da doença de Chagas se tornasse tanto um programa nacional quanto internacional, Emmanuel Dias exerceu um papel determinante para que a doença descoberta em Lassance, em 1909, se tornasse reconhecida não apenas no campo médico-científico, mas tam- bém como problema de saúde pública no Brasil e no continente americano.

Ao focalizarmos sua mobilização para conquistar tal reconhecimento, trouxemos à cena uma trajetória individual marcada pela intensidade da militância e do engajamento, que lhe emprestam contornos que podem ser vistos como "heroicos". No entanto, os sentidos desta trajetória - inclusive sua identidade enquanto "militante" da saúde - devem ser buscados justamente nas características peculiares da relação que este individuo estabeleceu com a sociedade na qual viveu e realizou suas escolhas, planos, estratégias e batalhas. Nesta perspectiva, o relevo de sua ação e disposição para conquistar os objetivos que o nortearam foi dado justamente pela amplitude das articulações que estabeleceu em torno de si e do projeto do qual se fez representante. É nesse sentido que, apesar de única e particular, sua trajetória pode ser vista como emblemática, a desvelar o papel de indivíduos e redes profissionais, políticas e sociais, em contextos históricos específicos, na construção da ciência e da saúde coletiva brasileiras.

\section{Agradecimentos}

Este artigo é dedicado ao Dr. João Carlos Pinto Dias, por sua luta - que foi a de seu pai - pela construção da saúde pública brasileira. 


\section{Referências}

1. Kropf SP. Doença de Chagas, doença do Brasil: ciência, saúde e nação (1909-1962). Rio de Janeiro: Editora Fiocruz; 2009.

2. Benchimol JL. Manguinhos, do sonho à vida. A ciência na Belle Époque. Rio de Janeiro: Casa de Oswaldo Cruz; 1990.

3. Dias JCP, organizador. Dr. Emmanuel Dias (19081962). Rio de Janeiro: Fundação Oswaldo Cruz; 2009.

4. Kropf SP. Carlos Chagas e os debates e controvérsias sobre a doença do Brasil (1909-1923). Hist. cienc. saude-Manguinhos. 2009; 16(Supl. 1):205-227.

5. Barreto DCS. Uma trajetória familiar na ciência: Evandro Chagas (1905-1940) e o estudo das endemias rurais no Brasil [dissertação]. Rio de Janeiro: Fiocruz; 2012.

6. Gomes AC. A Invenção do Trabalhismo. Rio de Janeiro, São Paulo: Iuperj, Vertice; 1988.

7. Dias E. O Centro de Estudos e Profilaxia de Moléstia de Chagas em Bambuí, Minas Gerais. Notícia histórica em homenagem ao Professor Henrique Aragão. Mem. Inst. Oswaldo Cruz 1956; 54(1):309-357.

8. Kropf SP. O coração do trabalhador: cardiologia e projeto nacional no Estado Novo. In: Andrade MM, Sedrez L, Martins WS, organizadores. Corpo: sujeito e objeto. Rio de Janeiro: Ponteio; 2012. p. 221-245.

9. Laranja F. Evolução dos conhecimentos sobre a cardiopatia da doença de Chagas. Mem. Inst. Oswaldo Cruz 1949; 47(3-4):605-669.

10. Dias E, Pellegrino J. Alguns ensaios com o gammexane no combate aos transmissores da doença de Chagas. Brasil-Médico 1948; 62(18-20):185-191.

11. Dias E. Apelo aos clínicos do interior para a colaboração no estudo da doença de Chagas. O Hospital 1942; 21(6):921-926.

12. Dias E. Instruções para captura e remessa de triatomídeos ou 'barbeiros'. Brasil-Médico 1943; 57(16/17): 197-198.

13. Romeiro OS. Encontro de caso agudo e de casos crônicos da doença no Estado de Goiaz. O Hospital 1941; 20(4):587-590.

14. Lasmar JE. Casos agudos de doença de Chagas em Bambuí, oeste de Minas Gerais. Brasil-Médico 1944; 58(23/24):232-233.

15. Falcão JB. Caso agudo de tripanosomose americana observado em Santo Angelo das Missões, Rio Grande do Sul. Brasil-Médico 1943; 57(14/15):179-182.

16. Menezes M. Miocardite chagásica crônica: sua incidência no Brasil Central. O Hospital 1949; 36(4):167-179.

17. Carta de Rubem Jácomo a Emmanuel Dias. Uberaba, 27/11/1947. Departamento de Arquivo e Documentação da Casa de Oswaldo Cruz/Fiocruz, Fundo Centro de Pesquisas René Rachou, Seção Posto Avançado de Pesquisa Emmanuel Dias, caixa 31, maço 2.

18. Jácomo R. Doença de Chagas em Uberaba. Rev. Soc. Med. Cirurgia de Uberaba 1950; 1(1):38-50.

19. Dias E. Doença de Chagas: noções. Rio de Janeiro: Ministério da Educação e Saúde/Serviço Nacional de Educação Sanitária; 1944.

20. Dias E. O 'barbeiro' e a doença de Chagas: Carlos Chagas e a grande descoberta de uma nova doença humana. Eu Sei Tudo, setembro de 1946.

21. Dulci OS. Política e recuperação econômica em Minas Gerais. Belo Horizonte: Editora UFMG; 1999.
22. Circular aos prefeitos. Minas Gerais; 1947 Junho 25.

23. Laranja F, Dias E, Nóbrega G. Clínica e terapêutica da doença de Chagas. Mem. Inst. Oswaldo Cruz 1948; 46(2):473-529.

24. Dias E. Controle das doenças transmitidas pelos triatomas. Bol. Ofic. Sanit. Panamericana 1948; 27(12):11601164.

25. Dias E. Considerações sobre a importância da moléstia de Chagas em Minas Gerais e estados vizinhos. BrasilMédico 1949; 63(34/35):217-220.

26. Dias E. Considerações sobre a Doença de Chagas. Mem. Inst. Oswaldo Cruz 1949; 47(3/4):679-685.

27. Pinotti M. Controle da doença de Chagas no Brasil. Rev. Bras. Malariologia e Doenças Tropicais 1954; 6(3):301-310.

28. Combate à moléstia de Chagas. Estado de Minas. 1950 Janeiro 15, p. 4.

29. Hochman G. From autonomy to partial alignment: national malaria programs in the time of global eradication, Brazil, 1941-1961. Can. Bull. Med. His. 2008; 25(1):161-192.

30. Carta de Emmanuel Dias a Joaquim Simões de Oliveira Filho. Bambuí, 8/12/1957. Departamento de Arquivo e Documentação da Casa de Oswaldo Cruz/ Fiocruz. Fundo Centro de Pesquisas René Rachou, Posto Avançado de Pesquisas Emmanuel Dias, caixa 33, maço 13

31. A doença de Chagas aniquila o caboclo paulista. $\mathrm{O} \mathrm{Cru}$ zeiro; 1957 Julho 27.

32. Solidário com 'O Globo' na campanha contra a doença de Chagas. O Globo; 1959 Janeiro 30.

33. Falta de transporte dificulta a luta contra o mal de Chagas. O Globo; 1959 Fevereiro 12

34. Dias E. Profilaxia da Doença de Chagas. O Hospital 1957; 51(3):285-298.

35. Winslow CEA. Lo que cuesta la enfermidad y lo que vale la salud. Washington: Organización Mundial de la Salud; 1955.

36. Dias E. Doença de Chagas: um problema americano. In: Proceedings of the Sixth International Congresses on Tropical Medicine and Malaria; 1958; Lisbon. p. 78-86.

37. Anais do Congresso Internacional sobre a Doença de Chagas. Rio de Janeiro: Oficina Gráfica da Universidade do Brasil; 1959/1964.

38. World Health Organization (WHO). Chagas' Disease: report of a Study Group. Geneva: WHO; 1960 (WHO Technical Report Series No. 202).

39. Vinhaes M, Dias JCP. Doença de Chagas no Brasil. Cad Saude Publica 2000; 16(Supl. 2):S7-S12.

40. Coura JR, Dias JCP. Epidemiology, control and surveillance of Chagas disease - 100 years after its Discovery. Mem. Inst. Oswaldo Cruz 2009; 104(Supl. I):31-40.

Artigo apresentado em 11/01/2016

Aprovado em 11/03/2016

Versão final apresentada em 13/03/2016 
